\title{
Publisher Correction: A 204-subject multimodal neuroimaging dataset to study language processing
}

\author{
Jan-Mathijs Schoffelen $\mathbb{D}^{1}{ }^{1}$, Robert Oostenveld $\mathbb{D}^{1,2}$, Nietzsche H. L. Lam ${ }^{1}$, Julia Uddén ${ }^{1,3,4,5}$, \\ Annika Hultén ${ }^{1,3,6}$ \& Peter Hagoort ${ }^{1,3}$
}

Correction to: Scientific Data https://doi.org/10.1038/s41597-019-0020-y, published online 03 April 2019

In the original version of this Data Descriptor, the author Annika Hultén was listed incorrectly as being affiliated with NatMEG, Karolinska Institutet, Stockholm, Sweden. This has been corrected in both the HTML and PDF versions to Max Planck Institute for Psycholinguistics, Nijmegen, The Netherlands.

(i) Open Access This article is licensed under a Creative Commons Attribution 4.0 International License, which permits use, sharing, adaptation, distribution and reproduction in any medium or format, as long as you give appropriate credit to the original author(s) and the source, provide a link to the Creative Commons license, and indicate if changes were made. The images or other third party material in this article are included in the article's Creative Commons license, unless indicated otherwise in a credit line to the material. If material is not included in the article's Creative Commons license and your intended use is not permitted by statutory regulation or exceeds the permitted use, you will need to obtain permission directly from the copyright holder. To view a copy of this license, visit http://creativecommons.org/licenses/by/4.0/.

(C) The Author(s) 2019

\footnotetext{
${ }^{1}$ Radboud University, Donders Institute for Brain, Cognition and Behaviour, Nijmegen, The Netherlands. ${ }^{2}$ NatMEG, Karolinska Institutet, Stockholm, Sweden. ${ }^{3}$ Max Planck Institute for Psycholinguistics, Nijmegen, The Netherlands. ${ }^{4}$ Stockholm University, Department of Psychology and Department of Linguistics, Stockholm, Sweden. ${ }^{5}$ Swedish Collegium for Advanced Study, Uppsala, Sweden. ${ }^{6}$ Department of Neuroscience and Biomedical Engineering, Aalto University, Espoo, Finland. Correspondence and requests for materials should be addressed to J.-M.S. (email: j.schoffelen@donders.ru.nl)
} 